\title{
EFFECT OF BORON CONCENTRATION ON FATIGUE CRACK PROPAGATION RESISTANCE AND LOW CYCLE FATIGUE PROPERTIES OF INCONEL 718
}

\author{
L. Xiao ${ }^{1}$, D.L. Chen ${ }^{2}$ and M.C. Chaturvedi ${ }^{1}$ \\ ${ }^{1}$ Department of Mechanical and Industrial Engineering, University of Manitoba, \\ Winnipeg, Manitoba R3T 5V6, Canada \\ ${ }^{2}$ Department of Mechanical and Industrial Engineering, Ryerson University, \\ 350 Victoria Street, Toronto, Ontario M5B 2K3, Canada
}

Keywords: Inconel 718, Boron concentration, Fatigue, Fatigue crack growth, Low cycle fatigue, Deformation mechanism

\begin{abstract}
The fatigue crack growth (FCG) rate and low cycle fatigue (LCF) life were determined in Inconel 718 (IN 718) alloy with 12 ppm and $29 \mathrm{ppm}$ boron (B) at room temperature. The results showed that B increased the FCG resistance and improved the LCF life of IN 718. The fatigue crack growth path in the alloy with the lower $\mathrm{B}$ concentration was relatively smooth and straight, whereas it was tortuous and rough in the higher B alloy. Transgranular fracture surfaces with some fatigue striations were observed. A large number of secondary cracks appeared on the fracture surface of LCF samples, particularly in the alloy with the lower B concentration. TEM examination of the plastic zone ahead of the crack tip in the FCG samples showed that the plastic deformation seems to be produced and accommodated by dislocation slip between grain boundaries and precipitates, and by the activation of mechanical twins. Precipitate-free deformation bands were also observed in the plastic zone ahead of the crack tip. The LCF deformation microstructures were observed to be regularly spaced arrays of planar deformation bands on the $\{111\}$ slip planes, consisting of characteristic diamond-shaped structures. A ladderlike microstructure was also observed in local regions in the fatigued IN 718 alloy with the lower B concentration. In the LCF specimens with a higher $\mathrm{B}$ concentration, the deformation substructure was composed of relatively uniformly distributed planar slip bands. The mechanisms which explain the effect of B on the fatigue properties of IN 718 are discussed.
\end{abstract}

\section{Introduction}

Inconel 718 (IN 718) is the most widely used superalloy in the gas turbine industry because of its attractive fabrication characteristics and high temperature properties, which are due in part to the presence of up to $60 \mathrm{ppm} \mathrm{B}$ in it. In these applications, the resistance to fatigue crack growth (FCG) and low cycle fatigue (LCF) is an important property. A considerable amount of work has been done to characterize the effect of loading waveform, temperature, environment and microstructure on the FCG and LCF behavior of IN 718 [1-10]. It is believed that in this alloy cracks initiate and propagate along planar deformation bands [18]. These bands lie on $\{111\}$ planes and are regularly spaced across the grain. Merrick [6] investigated the LCF of three wrought nickel base alloys: Waspaloy, Alloy 901 and Alloy 718, and demonstrated that for a given total strain range an increase in temperature from 298 to $811 \mathrm{~K}$ leads to a substantial reduction in fatigue life. However, little information is available in the open literature on the effect of B on the LCF and FCG characteristics of IN 718. The objective of this investigation was, therefore, to understand the effect of $\mathrm{B}$ on the fatigue properties and on the cyclic deformation mechanism of IN 718. Since B is known to adversely influence the weldability of IN 718, the results of this study would also help determine the minimum concentration of B needed, if any, to improve fatigue and fracture properties of IN 718 alloy.

\section{Materials and Experimental Procedures}

\section{$\underline{\text { Materials and Heat Treatment }}$}

Two wrought IN 718 based alloys, which had a similar base composition of (wt \%) $18.45 \% \mathrm{Cr}, 53.43 \% \mathrm{Ni}, 18.83 \% \mathrm{Fe}, 2.91 \%$ Mo, $4.86 \% \mathrm{Nb}$, but containing 12 and $29 \mathrm{ppm} \mathrm{B}$ and no C, S and $\mathrm{P}$ were produced by normal commercial practice for this research by Special Metal Corporation. Compact tension (CT) specimens for the fatigue crack growth (FCG) tests with a thickness of $12.7 \mathrm{~mm}$ were machined from the plate in the T-L orientation $(\mathrm{T}-$ transverse direction or the direction of least deformation, and $\mathrm{L}-$ longitudinal direction or the direction of principal deformation). Cylindrical specimens of $6.25 \mathrm{~mm}$ diameter and $10 \mathrm{~mm}$ gage length were used for the low-cycle fatigue (LCF) tests. The specimens were given the commercial heat treatment, which involved a solution treatment at $1227 \mathrm{~K}$ for one hour with the protective atmosphere of argon and then air cooled to room temperature (RT). They were then precipitation hardened by aging at $990 \mathrm{~K}$ for eight hours, cooled to $895 \mathrm{~K}$ at a rate of $50 \mathrm{~K} / \mathrm{h}$, and held at $895 \mathrm{~K}$ for a total aging time of eight hours then air cooled to RT.

\section{$\underline{\text { Fatigue Tests }}$}

The FCG and LCF tests were performed with a computerized Instron 8502 servo-hydraulic system, which was interfaced with a FastTrack 2 software for test control and data acquisition. FCG tests were conducted in the load-control mode using CT-type specimens. The tests were carried out at RT in air using a sine waveform with a load ratio $\left(\mathrm{R}=\mathrm{P}_{\min } / \mathrm{P}_{\max }\right)$ of 0.05 . Crack lengths were measured using a direct current potential drop technique. Load shedding procedure (in accordance with ASTM-E647 with a $K$ gradient, $C=(1 / K)(d K / d a)$, of -0.1$)$ was used to measure the fatigue threshold and near-threshold FCG rates. Symmetrical push-pull LCF tests were performed under total strain control. A 
triangle waveform with zero mean strain or $\mathrm{R}=-1$ was adopted with a nominal strain rate of $3 \times 10^{-3} \mathrm{~s}^{-1}$.

\section{Microstructural Examinations}

After fatigue failure, fatigue crack growth path was examined using an optical microscope. Fractographic analysis was carried out on the failed samples by JSM-5900LV scanning electron microscope (SEM). Extensive microstructural examination by means of JEM-2000FX transmission electron microscope (TEM) was performed both on the bulk LCF specimens and within the plastic zone surrounding fatigue cracks in order to correlate the fatigue behavior with the cyclic deformation structures. Thin foils of the plastic zone in the vicinity of the crack tip in the FCG specimens were prepared using a combination of precision dimpling, mechanical grinding and electro-polishing techniques. Thin foils of LCF specimens were prepared from discs cut from regions adjacent to the fracture surface and perpendicular to the loading axis. The electrochemical thinning was done at $243 \mathrm{~K}$ in a 10 pct Perchloric acid-Methanol bath at a potential of $12 \mathrm{~V}$.

\section{Experimental Results}

\section{Fatigue Crack Propagation Rate and Low Cycle Fatigue Lifetime}

Fig.1(a) depicts the fatigue crack growth rate $(\mathrm{da} / \mathrm{dN})$, as a function of stress intensity factor range $\left(\Delta K=K_{\max }-K_{\min }\right)$ in IN 718 alloy with different concentrations of $\mathrm{B}$. It is seen that the FCG rate decreased as B concentration increased from $12 \mathrm{ppm}$ to $29 \mathrm{ppm}$, especially in the near-threshold region. The fatigue crack propagation threshold, $\Delta \mathrm{K}_{\mathrm{th}}$, which was defined as the $\Delta \mathrm{K}$ corresponding to a growth rate of $10^{-10} \mathrm{~m} /$ cycle, increased from 7.6 to $8.6 \mathrm{MPa} \sqrt{\mathrm{m}}$ at RT as the B concentration increased from $12 \mathrm{ppm}$ to $29 \mathrm{ppm}$. This suggests that B has a beneficial effect on the near-threshold FCG resistance of IN 718 within the considered $\mathrm{B}$ concentrations. The obtained da/dN- $\Delta \mathrm{K}$ data appear to conform to the Paris law from the onset of the fatigue threshold, which are given in Table I.

Table I. Paris Parameters of IN 718 with Different Concentrations of B

\begin{tabular}{|c|c|}
\hline B (ppm) & Paris Law \\
\hline 12 & $\mathrm{da} / \mathrm{dN}=2 \times 10^{-16} \Delta \mathrm{K}^{6.53}$ \\
29 & $\mathrm{da} / \mathrm{dN}=3 \times 10^{-17} \Delta \mathrm{K}^{7.05}$ \\
\hline
\end{tabular}

The LCF lifetime $\left(\mathrm{N}_{\mathrm{f}}\right)$ curves as a function of cyclic plastic strain amplitude $\left(\Delta \varepsilon_{\mathrm{p}} / 2\right)$ were established for the both alloys, as shown in Fig.1(b). The results show that B has a significant influence on LCF life of IN 718 as well. The LCF life of the alloy increased with increasing concentration of boron at a given plastic strain amplitude. With bi-logarithmic coordinates, the $\Delta \varepsilon_{\mathrm{p}} / 2-\mathrm{N}_{\mathrm{f}}$ curves obtained in this study appear complex. They exhibit two slopes and an inflection point occurs at $\Delta \varepsilon_{\mathrm{p}} / 2=0.28 \%$. A similar "TwoSlope" relationship between the fatigue life and the cyclic plastic strain amplitude was also reported for IN 718 tested at RT by Clavel and Pineau [3] and Sarders et al. [9]. Concerning the data analysis of LCF life, the well-known Manson-Coffin equation is often used to describe the relationship between the fatigue life and the cyclic plastic strain amplitude, and to predict the fatigue life of structural materials. The four Manson-Coffin type relationships, shown in Table II, have been obtained for the alloys studied.
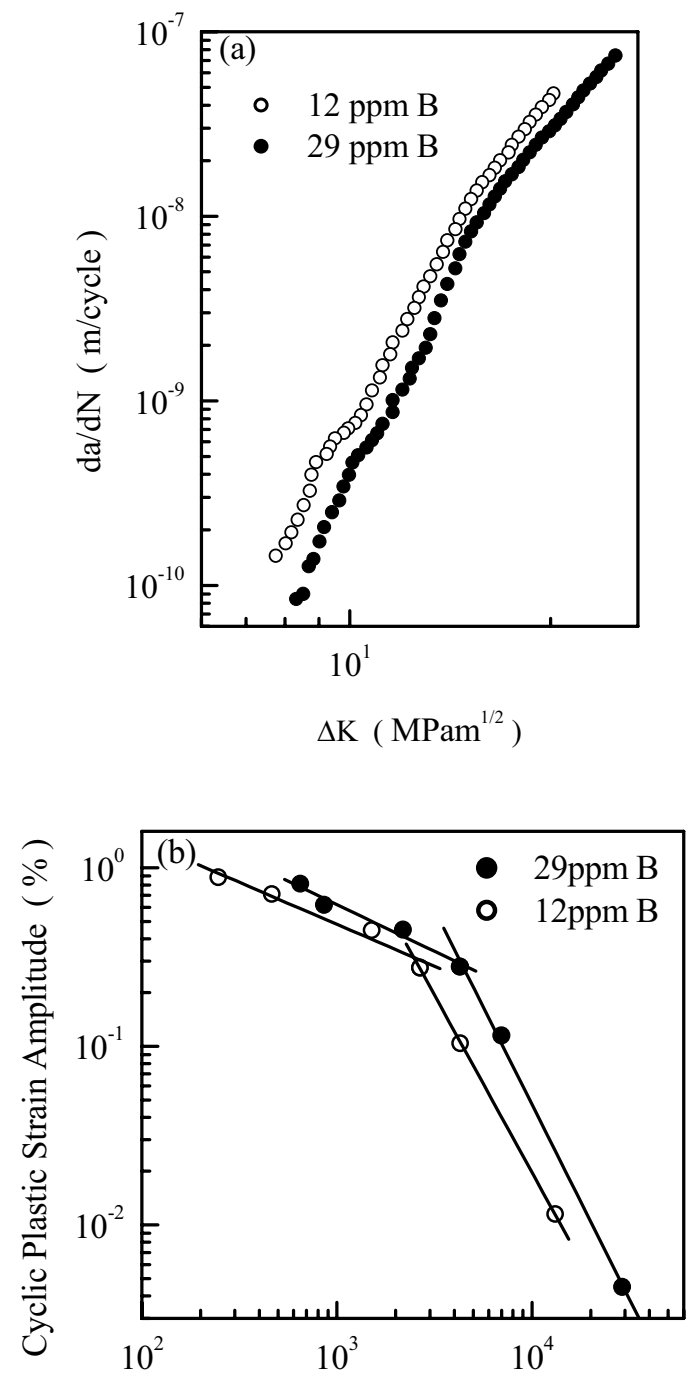

Fatigue Lifetime ( cycles )

Figure 1. Influence of boron concentration on the fatigue crack growth behavior and low cycle fatigue lifetime of IN 718, (a) FCG, da/dN- $\Delta \mathrm{K}$, and (b) LCF, $\Delta \varepsilon_{\mathrm{p}} / 2-\mathrm{N}_{\mathrm{f}}$.

Table II. The Coffin-Manson Relationship for IN 718

\begin{tabular}{|c|c|c|}
\hline $\mathrm{B}(\mathrm{ppm})$ & $\Delta \varepsilon_{\mathrm{p}} / 2 \geq 0.28 \%$ & $\Delta \varepsilon_{\mathrm{p}} / 2 \leq 0.28 \%$ \\
\hline 12 & $\Delta \varepsilon_{\mathrm{p}} \mathrm{N}_{\mathrm{f}}{ }^{0.373}=6.96$ & $\Delta \varepsilon_{\mathrm{p}} \mathrm{N}_{\mathrm{f}}{ }^{1.774}=2.6 \times 10^{5}$ \\
29 & $\Delta \varepsilon_{\mathrm{p}} \mathrm{N}_{\mathrm{f}}{ }^{0.452}=14.29$ & $\Delta \varepsilon_{\mathrm{p}} \mathrm{N}_{\mathrm{f}}{ }^{1.854}=1 \times 10^{6}$ \\
\hline
\end{tabular}

Fatigue Crack Propagation Path and Fracture Surface

Metallographic examinations indicated that the fatigue crack growth path in the alloy with lower B (12 ppm) displayed a smooth and straight growth path (Fig.2(a)), whereas it was tortuous and rough in the higher B alloy (Fig.2(b)). Some plastic deformation marks could be observed in the region of fatigue crack propagation as indicated by an arrow in Fig.2(b). Thus, the improved FCG resistance can be attributed to the enhancement of the fatigue crack closure induced by the fracture surface 


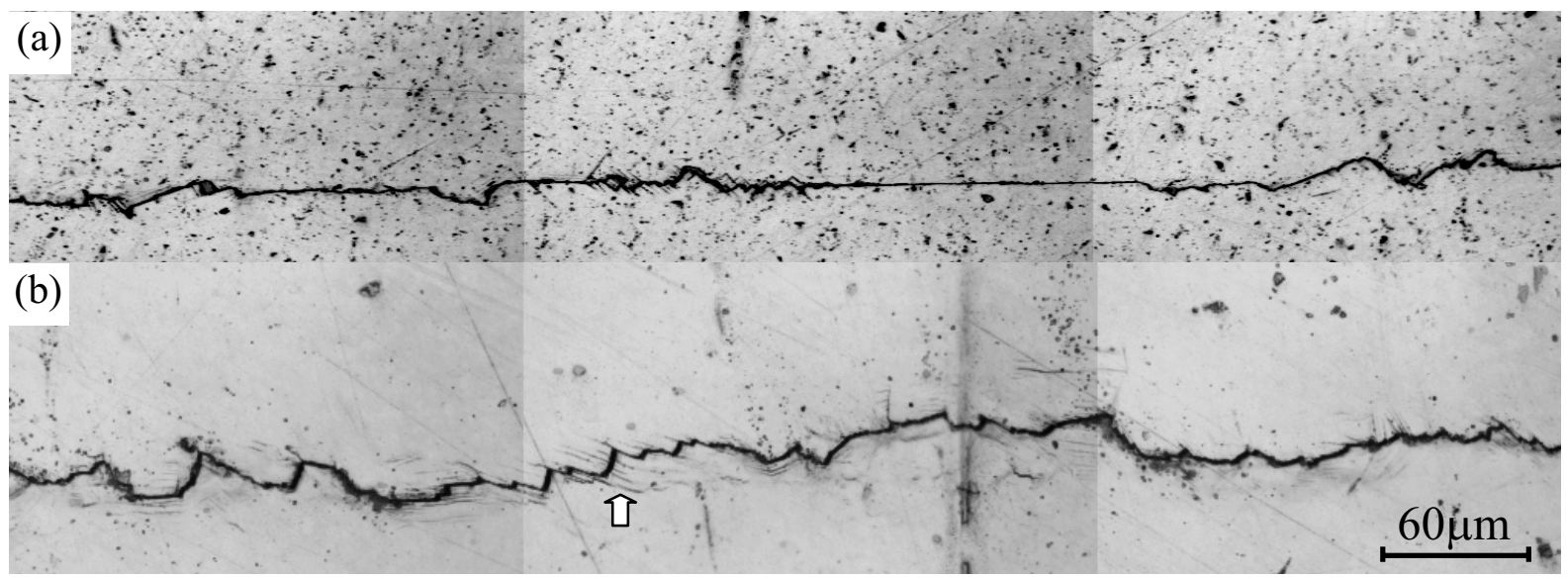

Figure 2. Fatigue crack growth paths for IN 718 with different concentrations of B, (a) 12 ppm B, and (b) 29 ppm B.
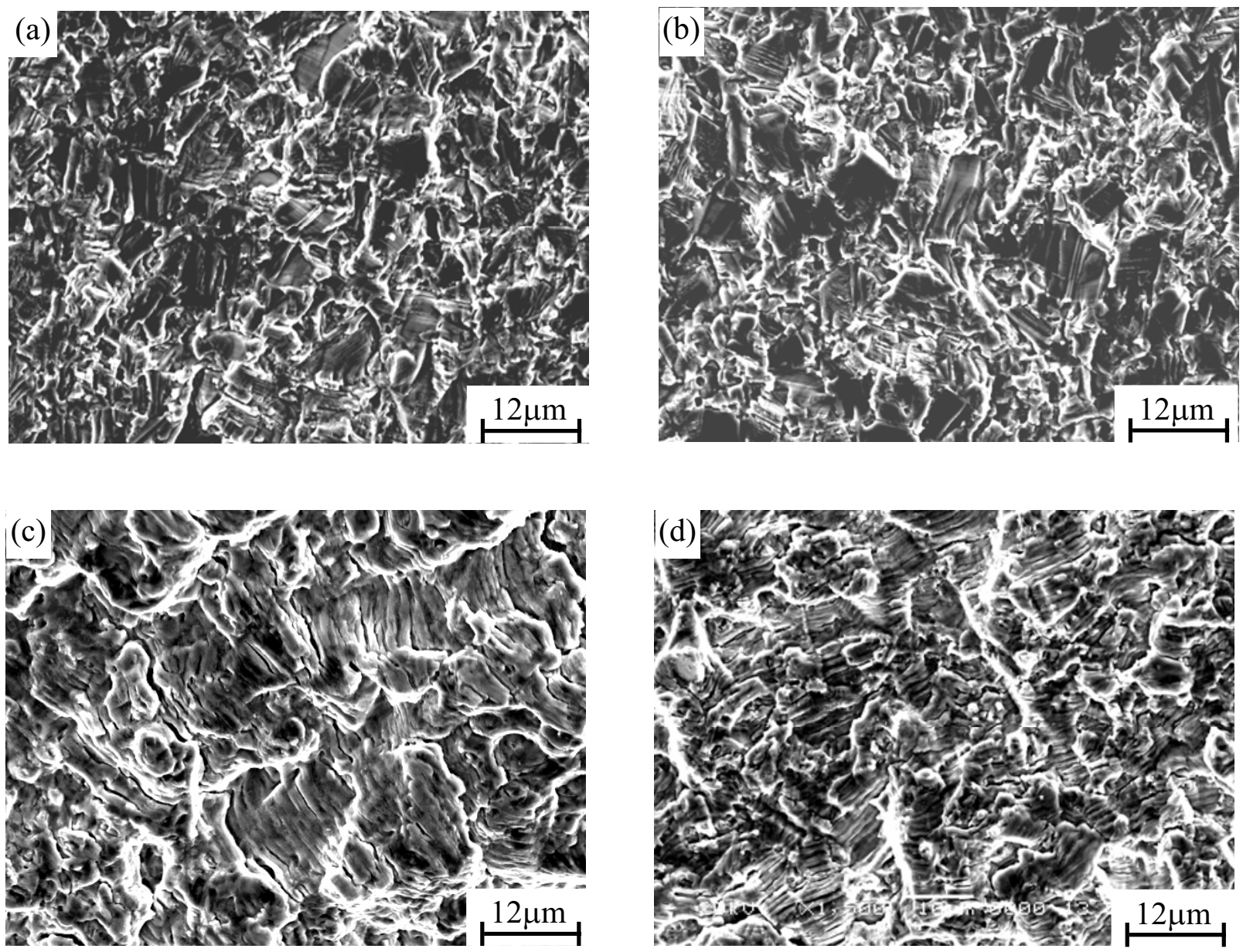

Figure 3. Typical fracture surfaces of IN 718 with different concentrations of B after FCG and LCF tests, (a) 12 ppm B, FCG, (b) $29 \mathrm{ppm} \mathrm{B}, \mathrm{FCG}$, (c) $12 \mathrm{ppm} \mathrm{B}, \Delta \varepsilon_{\mathrm{t}} / 2=0.4 \%$, LCF, and (d) $29 \mathrm{ppm} \mathrm{B}, \Delta \varepsilon_{\mathrm{t}} / 2=0.4 \%$, LCF. 
roughness in alloy with the higher B concentration (Fig.2(b)), in comparison to the lower B alloy (Fig.2(a)).

The fractographic examination suggested that in the FCG specimens with different concentrations of $\mathrm{B}$ the fracture mode in the low $\Delta \mathrm{K}$ region was transgranular with an appearance of crystallographic cracking, while fatigue striations developed in the stable crack growth regime (Figs.3(a) and (b)). This mode of fracture suggests that the crack grows by the usual plastic blunting-sharpening mechanism (i.e., Laird model). No obvious difference in the fatigue crack growth mode could be determined between these two alloys.

The typical fractographs of IN 718 after LCF tests are shown in Figs.3(c) and (d). For both alloys fatigue crack propagation was primarily characterized by the well-defined fatigue striations, which are taken as an evidence of transgranular crack growth at RT. A large number of secondary cracks were observed on fracture surfaces of both the alloys. However, the amount of secondary cracks in the alloy with a lower B concentration (Fig.3(c)) is more than that observed in the alloy with a higher B concentration (Fig.3(d)).

\section{Deformation Substructures}

TEM examination of the plastic zone in front of the crack tip showed that a single slip system was activated, and the plastic deformation seems to be produced and accommodated by dislocation slip between grain boundaries and precipitates, as shown in Fig.4(a). This regime corresponds to the near-threshold FCG region. It was also observed that the near-threshold regime was still characterized by the occurrence of mechanical twins, as shown in Fig.4(b). Precipitate-free deformation bands were observed in the plastic zone in IN 718 with higher B (Fig.4(c)). This is closely related to the fact that $\gamma^{\prime \prime}$ particles are sheared by dislocations. The shearing mechanism of $\gamma^{\prime \prime}$ particles has been already discussed by several authors $[3,5,11,12]$. The repeated shearing of ordered $\gamma^{\prime \prime}$ precipitates in successive cycles leads to a reduction in their size. Consequently, the stress necessary to shear the precipitates during repeated cycles is reduced, which eventually offers a resistance-free (precipitate-free) path for the dislocation movement $[3,5]$.

The deformation microstructures produced by LCF in IN 718 alloys with $12 \mathrm{ppm}$ and $29 \mathrm{ppm}$ B were also examined by TEM. Regularly spaced arrays of planar deformation bands on $\{111\}$ slip planes were observed in the fatigued specimen with $12 \mathrm{ppm} \mathrm{B}$ (Figs.5(a)). Trace analysis showed that $(1 \overline{1} \overline{1})$ and (11 $\overline{1})$ double slip systems were activated simultaneously, giving rise to the saturated diamond-shaped deformation structure. In the LCF specimens with $29 \mathrm{ppm} \mathrm{B}$, the deformation substructure was composed of planar slip bands (Fig.5(b)), and the distribution of the planar slip was homogeneous. On a closer examination, a ladder-like microstructure was observed in local regions in the LCF specimens with the lower B concentration (Fig.6). This implies that some wavy slip was activated locally due to the crossslip, leading to a configuration analogous to the persistent slip bands (PSBs) produced in IN 718 with the lower B concentration.

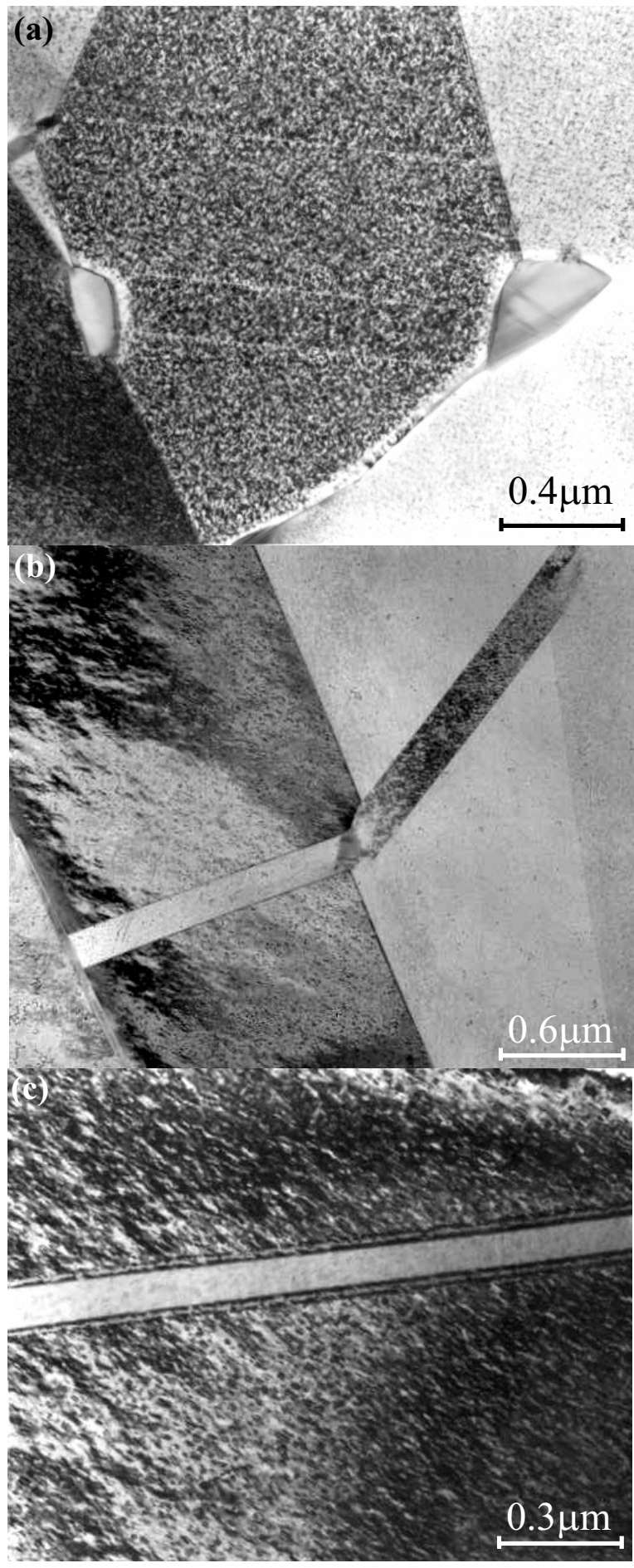

Figure 4. Transmission electron micrographs showing deformation substructures of IN 718 in the crack-tip region corresponding to the near-threshold regime, (a) Planar deformation bands in alloy with 12 ppm B, (b) Deformation twins in alloy with $12 \mathrm{ppm} \mathrm{B}$, and (c) Deformation band devoid of precipitates in alloy with $29 \mathrm{ppm}$ B. 

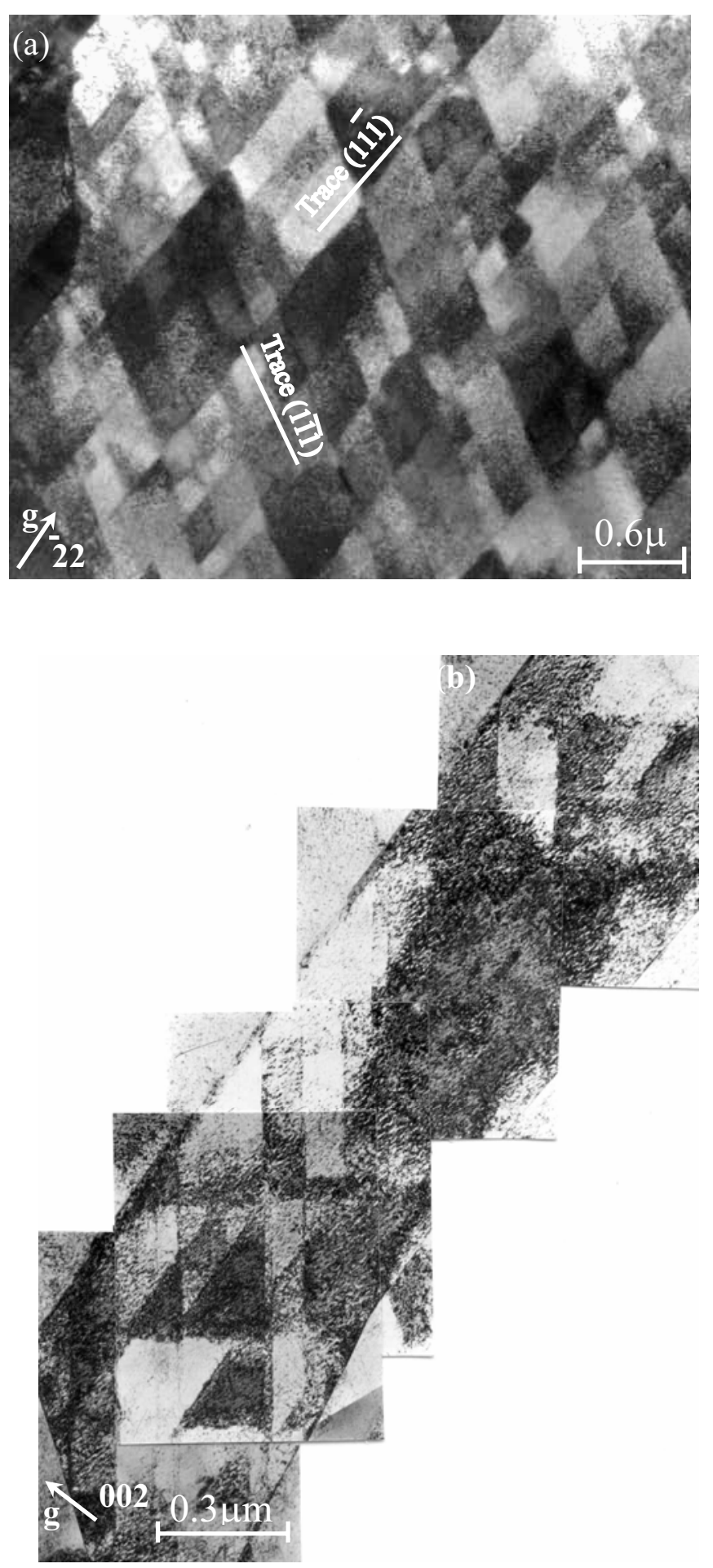

Figure 5. Typical deformation structures in LCF specimens, (a) Alloy with 12 ppm B, $\Delta \varepsilon_{\mathrm{t}} / 2=1.0 \%, \mathrm{~N}_{\mathrm{f}}=1558,(\widetilde{\mathbf{g}}=\overline{2} 20$; incident beam // [111] ), and (b) Alloy with $29 \mathrm{ppm} \mathrm{B,} \Delta \varepsilon_{\mathrm{t}} / 2=1.4 \%$, $\mathrm{N}_{\mathrm{f}}=650,(\widetilde{\mathbf{g}}=3 \overline{1} \overline{1}$; incident beam // [233] $)$.

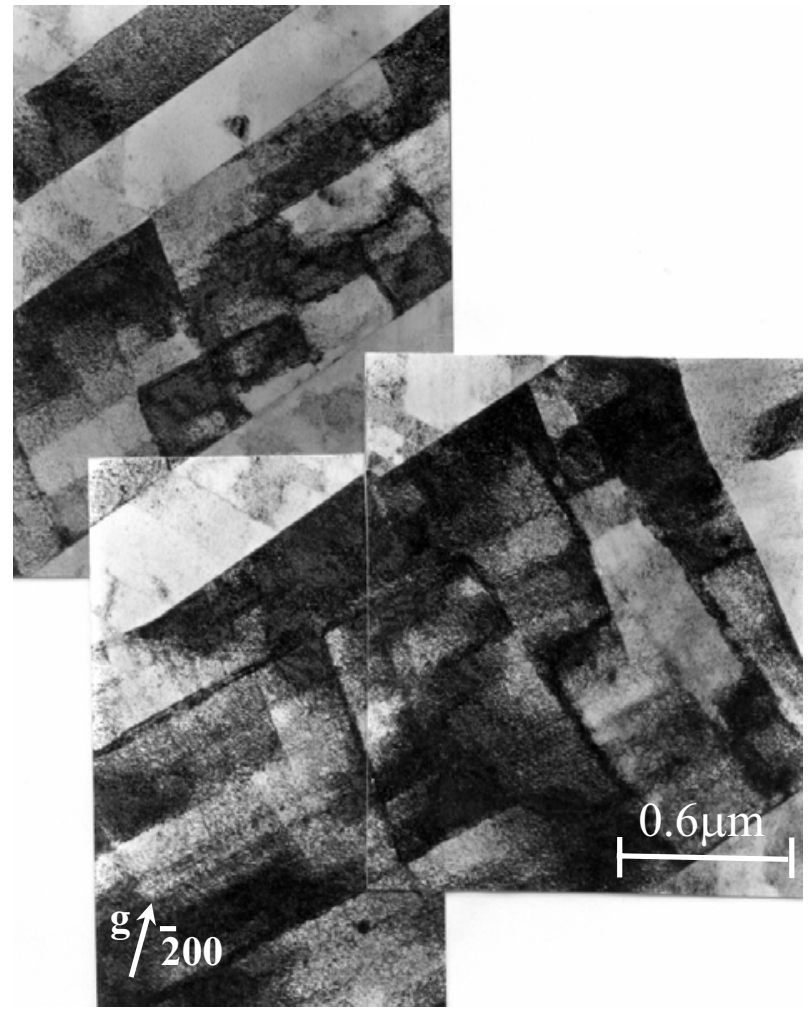

Figure 6. A ladder-like structure formed in the LCF specimen of IN 718 with $12 \mathrm{ppm} \mathrm{B,} \Delta \varepsilon_{\mathrm{t}} / 2=0.8 \%, \mathrm{~N}_{\mathrm{f}}=1015$, ( $\widetilde{\mathbf{g}}=\overline{2} 00 ;$ incident beam $/ /[012])$.

\section{Discussion}

The effect of $\mathrm{B}$ on fatigue crack propagation behavior and low cycle fatigue life of IN 718 was studied in this investigation. It was found that B increased the resistance to FCG and improved the LCF lifetime. These results can be rationalized on the basis of the mechanisms associated with the interaction of dislocations with interstitial element $B$, and with precipitates ( $\gamma^{\prime \prime}$ and boride). One possible mechanism responsible for the improvement in the FCG resistance and the LCF life of IN 718 by B addition could be the retardation of dislocation slip by direct elastic interaction between dislocations and $\mathrm{B}$ atoms in solution, and by boride particles. As an interstitial element, B atoms may form clusters which, along with boride precipitate particles, would act as obstacles to the dislocation movement, impede the dislocation slip, and thus enhance the FCG resistance and the LCF life of IN 718.

Another possible mechanism is through the interaction of B with dislocations, which makes it difficult for deformation to occur either by dislocation glide on the slip plane or by cross-slip. Some wavy slip character associated with the cross-slip was produced in localized regions of IN 718 with the lower B concentration, and a ladder-like structure was observed (Fig.6). This indicates that the cross-slip becomes easier in IN 718 with the lower B than that with the higher $\mathrm{B}$ concentration. Wavy slip induces the concentration of slip in a few bands within the bulk of the material, which leads to the formation of PSBs and increases the 
stress concentration within PSBs, and thus serves as potential microcrack initiation sites. Microscopically, strong dislocation piles and high stress concentration lead to fatigue crack nucleation and favor crack propagation, thereby decrease the fatigue life of IN 718 with the lower B. The larger amount of secondary cracks observed on the fracture surface of samples with the lower B than with the higher B, as shown in Fig.3(c) and (d), also corroborate the occurrence of local fracture due to the strain localization in alloy with $12 \mathrm{ppm}$ B. Good fatigue properties are always associated with a planar slip character and a high degree of slip dispersal [13].

Furthermore, an improvement in fatigue properties of IN 718 by B addition could be related to the increased grain boundary cohesion due to B segregation. Stress and strain concentrations at the grain boundary region, induced by a lack of sufficient number of slip, can be accommodated by either intergranular cracking or transgranular cracking, depending on the cohesion strength of the grain boundaries relative to that of the bulk material. Boron containing precipitate particles were observed at grain boundaries (Figs.7(a) and (b)), and a strong evidence of segregation of B at grain boundaries has been observed by SIMS analysis in the earlier studies on the weldability of IN 718 [14, 15]. It is, therefore, believed that boron segregation has a beneficial effect on the FCG resistance and LCF lifetime of IN 718 via the increased grain cohesion.
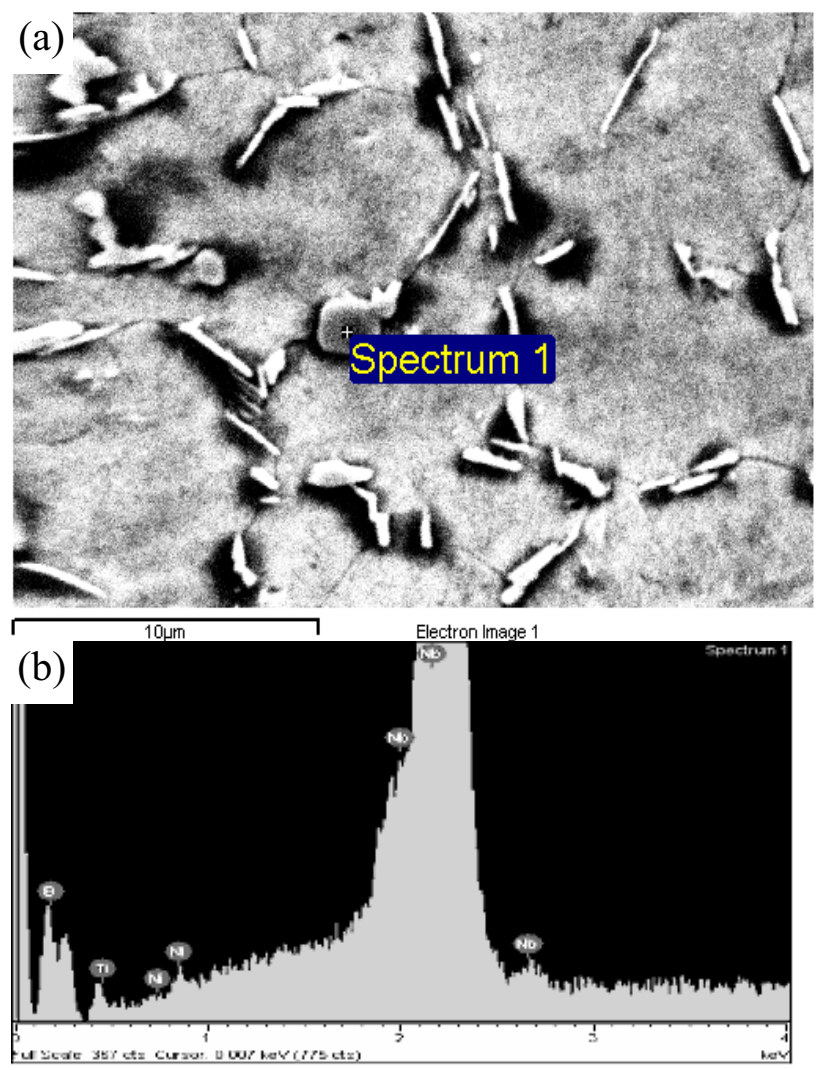

Figure 7. Boride formed on the grain boundary in IN 718 with 29 ppm B, (a) SEM micrograph, and (b) EDS.

\section{Conclusions}

1. The fatigue crack growth rate of IN 718 alloy tested at room temperature decreased and the fatigue threshold, $\Delta \mathrm{K}_{\mathrm{th}}$, increased from 7.6 to $8.6 \mathrm{MPa} \sqrt{\mathrm{m}}$, as the boron concentration increased from $12 \mathrm{ppm}$ to $29 \mathrm{ppm}$.

2. The low cycle fatigue life of IN 718 increased with increasing concentration of boron from $12 \mathrm{ppm}$ to $29 \mathrm{ppm}$ at a given plastic strain amplitude. The fatigue lifetime vs. the cyclic plastic strain amplitude curves exhibited a two-stage linear relationship in the bi-logarithmic coordinates, and the transition occurred at a cyclic plastic strain amplitude of $0.28 \%$.

3. The fatigue crack growth path in alloy with the lower B (12 ppm) alloy was relatively smooth and straight, whereas in the higher B alloy it was tortuous and rough with some evidence of plastic deformation.

4. Fractographic examinations of the fatigue crack growth specimens suggested the fracture to be transgranular with fatigue striations. The typical LCF fracture morphologies were also transgranular, coupled with a large number of secondary cracks on the fracture surface especially in the alloy with the lower B. Well-defined fatigue striations were observed in the LCF specimens.

5. TEM examination of the plastic zone ahead of the crack tip showed that the plastic deformation seems to be produced and accommodated by dislocation slip and mechanical twins. Precipitate-free deformation bands were observed within the plastic zone in the fatigue crack growth specimens.

6. The deformation microstructures produced after low cycle fatigue tests in IN 718 alloys with 12 ppm and 29 ppm B were observed to be regularly spaced arrays of planar deformation bands on $\{111\}$ slip planes, consisting of characteristic diamond-shaped structures. A ladder-like structure was also observed in the local region in the fatigued specimen with the lower B concentration. In the low cycle fatigue specimens with the higher $\mathrm{B}$, the deformation substructure was composed of planar slip bands which have a relatively homogeneous distribution.

\section{Acknowledgments}

The authors are grateful to NSERC of Canada and a Consortium of Manitoba Aerospace Industries for the financial support.

\section{References}

1. D. Fournier and A. Pineau, "Low Cycle Fatigue Behavior of Inconel 718 at $298 \mathrm{~K}$ and $823 \mathrm{~K}$," Metall. Trans. A, 8A(1977), 1095-1105.

2. M. Clavel and A. Pineau, "Frequency and Wave-Form Effects on the Fatigue Crack Growth Behavior of Alloy 718 at 298K and $823 \mathrm{~K}$," Metall. Trans. A, 9A(1978), 471-480.

3. M. Clavel and A. Pineau, "Fatigue Behaviour of Two Nickelbase Alloys I: Experimental Results on Low Cycle Fatigue, Fatigue Crack Propagation and Substructures," Mater. Sci. Eng., 55(1982), 157-171. 
4. C. Mercer and W. O. Soboyejo, "Fatigue Crack Growth Mechanisms in a Forged IN 718 Nickel-Based Superalloy," Superalloys 718, 625, 706 and Various Derivatives (Edited by E. A. Loria, The Minerals, Metals \& Materials Society, 1997), 577-586.

5. S. Kalluri et al., "Deformation and Damage Mechanisms in Inconel 718 Superalloy," Superalloys 718, 625, 706 and Various Derivatives (Edited by E. A. Loria, The Minerals, Metals \& Materials Society, 1994), 593-606.

6. H. F. Merrick, "The Low Cycle Fatigue of Three Wrought Nickel-Base Alloys,” Metall. Trans., 5(1974), 891-897.

7. J. L. Yuen, P. Roy and W. D. Nix, "Effect of Oxidation Kinetics on the Near Threshold Fatigue Crack Growth Behavior of a Nickel Base Superalloy," Metall. Trans. A, 15A(1984), 1769-1775.

8. L. A. James and W. J. Mills, "Effect of Heat-Treatment Upon the Fatigue-Crack Growth Behavior of Alloy 718 Weldments - Part I: Macroscopic Behavior," ASME J. of Eng. Mater. Tech., 107(1985), 34-40.

9. T. H. Sanders, Jr., R. E. Frishmuth and G. T. Embley, "Temperature Dependent Deformation Mechanisms of Alloy
718 in Low Cycle Fatigue," Metall. Trans. A, 12A(1981) 1003-1010.

10. D. W. Worthem et al., "Inhomogeneous Deformation in INCONEL 718 during Monotonic and Cyclic Loadings," Metall. Trans. A, 21A(1990), 3215-3220.

11. I. Kirman and D. H. Warrington, "The Precipitation of $\mathrm{Ni}_{3} \mathrm{Nb}$ Phases in a Ni-Fe-Cr-Nb Alloy," Metall. Trans., 1(1970), $2667-2675$

12. M. Sundararaman, P. Mukhopadhyay and S. Banerjee, "Deformation Behaviour of $\gamma^{\prime}$ Strengthened Inconel 718," Acta Metall., 36(1988), 847-864.

13. L. Xiao, Y. Umakoshi and J. Sun, "Cyclic Deformation Behavior and Microstructures of Hydrided Zircaloy-4 under Biaxial Loading," Metall. Mater. Trans. A, 32A(2001), 2841-2850.

14. X. Huang et al., "The effect of Grain Boundary Segregation of Boron in Cast Alloy 718 on HAZ Microfissuring - A SIMS Analysis," Acta Mater., 45(1997), 3095-3107.

15. W. Chen and M. C. Chaturvedi, "Dependence of Creep Fracture of Inconel 718 on Grain Boundary Precipitates," Acta Mater., 45(1997), 2735-2746. 
